\title{
Correction to: Striatal-frontal network activation during voluntary task selection under conditions of monetary reward
}

\author{
Joseph M. Orr ${ }^{1,2} \cdot$ Michael J. Imburgio ${ }^{1}$ Jessica A. Bernard ${ }^{1,2} \cdot$ Marie T. Banich ${ }^{3,4}$
}

Published online: 25 February 2019

(C) The Psychonomic Society, Inc. 2019

\section{Correction to: Cognitive, Affective, \& Behavioral Neuroscience https://doi.org/10.3758/s13415-019-00689-0}

Conflict of interest statement: Although co-author Marie T. Banich is the Editor-in-Chief of Cognitive, Affective, and Behavioral Neuroscience, Stan Floresco served as the action editor for this manuscript

Publisher's note Springer Nature remains neutral with regard to jurisdictional claims in published maps and institutional affiliations.

The online version of the original article can be found at https://doi.org/ 10.3758/s13415-019-00689-0

\section{Joseph M. Orr}

joseph.orr@tamu.edu

1 Department of Psychological and Brain Sciences, Texas A\&M University, 515 Coke Street, College Station, TX 77843-4235, USA

2 Texas A\&M Institute for Neuroscience, Texas A\&M University, College Station, TX, USA

3 Institute of Cognitive Science, University of Colorado Boulder, Boulder, CO, USA

4 Department of Psychology and Neuroscience, University of Colorado Boulder, Boulder, CO, USA 